\title{
Improvement of New PCR Assay Targeting Mutations for Fast Recognition of Azole Resistant Mould Fungus, Aspergillus fumigatus ${ }^{\dagger}$
}

\section{Theyyathel A.M. ${ }^{1}$, Anima Nanda ${ }^{1, *}$, B.K. Nayak ${ }^{2}$}

1 Department of Biomedical Engineering, Sathyabama Institute of Science and Technology, Deemed to be University, Chennai- 600119

2 Department of Botany, K. M. Govt. Institute for Postgraduate Studies and Research (Autonomous), Puducherry-605008

* Correspondence: animananda72@gmail.com;

$\dagger$ Presented at International e-Conference on Bioengineering for Health and Environment (ICBHE 2020)

Received: 5.07.2020; Revised: 10.07.2020; Accepted: 12.07.2020; Published: 15.07.2020

\begin{abstract}
Allergenic mould fungus, Aspergillus fumigatus well known for its invasive aspergillosis disease is intrinsically resistant to most of the fluconazole group of medicines. It was studied that the mutations encoding 14a-sterol demethylase has the capacity to make triazole-resistant to this clinical fungal isolates. The present study is a multiplex allele-specific PCR assay targeting mutations for rapid detection of azole-resistant $A$. fumigatus for suitable patient management. During the present work clinical and wild isolates of $A$. fumigatus were employed to evaluate MAS-PCR, which was confirmed by direct DNA sequencing of cyp5 IA98 region from selected isolates of A. fumigatus. MAS-PCR assay was successfully developed to simplify the rapid detection of L98H mutation in cyp51A gene that confers the resistance to triazoles in A. fumigatus strains. The assay would help in primary acknowledgement of triazole-resistant A. fumigatus strains for proper management of patients with invasive aspergillosis.
\end{abstract}

Keywords: MAS-PCR assay; Aspergillus fumigatus; triazole-resistant; invasive aspergillosis.

(C) 2020 by the authors. This article is an open access article distributed under the terms and conditions of the Creative Commons Attribution (CC BY) license (https://creativecommons.org/licenses/by/4.0/).

\section{Funding}

This research received no external funding.

\section{Acknowledgments}

This research has no acknowledgment.

\section{Conflicts of Interest}

The authors declare no conflict of interest. 